\title{
Temperature monitoring of surface layers of the earth in Perm
}

\author{
Andrey Ponomaryov ${ }^{1, *}$, and Aleksandr Zakharov ${ }^{1}$ \\ ${ }^{1}$ Perm National Research Polytechnic University, 29 Komsomolskyi prospekt St, Perm, 614000, \\ Russia
}

\begin{abstract}
The article presents the results of monitoring the temperature of the surface layers of the earth. Monitoring was carried out at two sites with engineering-geological conditions typical for Perm. The geological conditions of the first site are clay soils, the second site is sandy. The first site is located in a dense urban development, the second in an unfinished part of the city of Perm. The depth of the soil massif on which the temperature was monitored was: for the first site $-19 \mathrm{~m}$, for the second site - $37 \mathrm{~m}$. Based on monitoring results, a picture of the temperature change in the soil massif in time for both sites was obtained. In the article, the average monthly temperatures of the soil massif are plotted on both sites. The zone of fluctuations in the temperature of the soil massif is revealed depending on the temperature of the outside air. The depth of the zone of seasonal temperature fluctuations was $10 \mathrm{~m}$. Monitoring determined that the temperature of the ground mass is below $10 \mathrm{~m}$ : for the first site $+12{ }^{\circ} \mathrm{C}$ with a decrease in temperature to $10^{\circ} \mathrm{C}$ to a depth of $19 \mathrm{~m}$, for the second site - a constant $+6-7^{\circ} \mathrm{C}$ to a depth of $37 \mathrm{~m}$.
\end{abstract}

\section{Introduction}

The Department of Construction Technology and Geotechnics of Perm National Research Polytechnic University has conducted studies of temperature fields of ground bases in the city of Perm since 2009. Research is being carried out to quantify the soil thermal behavior for the main types of geotechnical conditions. Quantitative assessment of subgrade temperature is one of the main factors allowing introduce process based on the use of the soil thermal energy.

In particular, they are energy-efficient foundations and underground structures of buildings. As a rule, the technologies based on the use of the soil thermal energy are employed for heating and cooling of buildings, at least - in order to provide electricity and hot water.

These technologies have been widely used in European and neighboring countries [1-5]. Their introduction in Russia is point and did not found mass distribution.

\footnotetext{
*Corresponding author: spstf@pstu.ru
} 


\section{Geological section of experimental sites}

Research of temperature fields of ground bases carried out for two basic types of geotechnical conditions specific to the left-bank and right-bank parts of the Perm city. Studies are being conducted at two sites:

Site 1. The monitoring system is installed at the Civil Engineering Faculty PNRPU in the Sverdlovsky district of Perm (left bank of the city of Perm). Monitoring has been carried out continuously since December 2008 to the present.

Site 1 is characterized by dense urban development. Development age is more than 50 years. The distance from the observation well to the nearest building is about $3 \mathrm{~m}$.

In accordance with the results of geological engineering survey experimental site 1 is comprised of quaternary alluvial- dealluvial clayey soil of the total thickness of $11.6 \mathrm{~m}$, with up to $60-70 \%$ of pebbles at the bottom. Quaternary soils are overlaid by filled-up ground of the thickness of $6.0 \mathrm{~m}$.

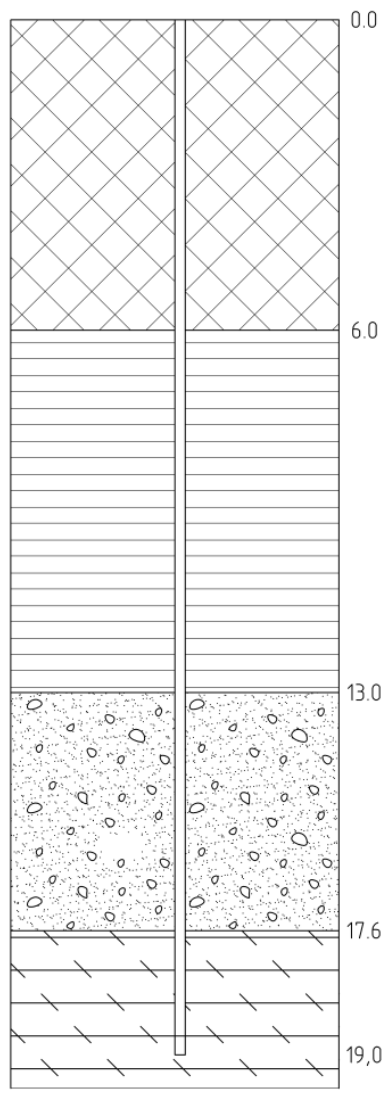

a) Site 1

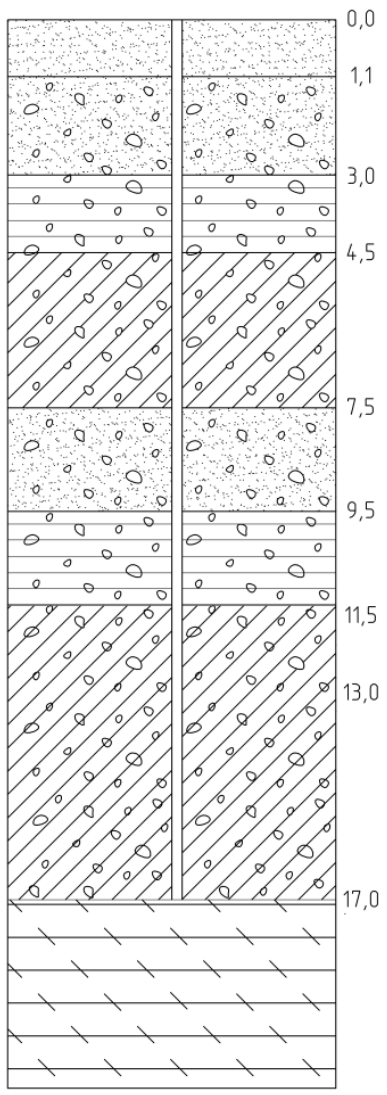

b) Site 2

Fig. 1. Geological section of experimental sites.

Bedrock is argillites uncovered at a depth of $17.6 \mathrm{~m}$.

Filled-up ground is presented by clay soil of semi-solid to plastic consistency at the base with an admixture of $60-70 \%$ of construction waste (rubble, broken bricks, glass, wood).

Quaternary alluvial- dealluvial deposits are mainly represented by clay of solid to semisolid consistency underlying the pebble with loamy sand of solid consistency (content of gravel and pebbles is $60-70 \%$ ). 
Geological section is shown in Fig. 1a.

Site 2 . The monitoring system is installed on the territory of the university campus in the Leninsky district of Perm (right bank of the city of Perm.). Monitoring has been carried out since August 2015. Currently monitoring data were obtained till January 2016.

Site 2 is located on the undeveloped area of the city. The distance to the nearest building is more than $30 \mathrm{~m}$.

According to the results of archival research of surrounding area site 1 is comprised of quaternary alluvial sand and clay of the total thickness of $15 \mathrm{~m}$, with $25 \%$ of gravel at the bottom. Quaternary alluvial deposits are represented by fine sand, clay and clay soils of plastic to liquid consistency. The gravel inclusion was marked from a depth of $1.0 \mathrm{~m}$ along the full thickness of the alluvial soils with an increase to the base up to $25 \%$. According to the results of archive research the bedrock was uncovered at a depth of $17.0 \mathrm{~m}$.

Geological section is shown in Fig. 1b.

According to the results of geotechnical studies sites 1 and 2 are assigned to the I and II types of geotechnical conditions, respectively, specific to Perm [6].

\section{Monitoring of the temperature fields results}

Studies of the temperature field distribution in the soil are carried out by installing of the resistive temperature transducer (temperature sensors). Installation of resistive temperature transducer was made in a pre-drilled hole under the protection casing.

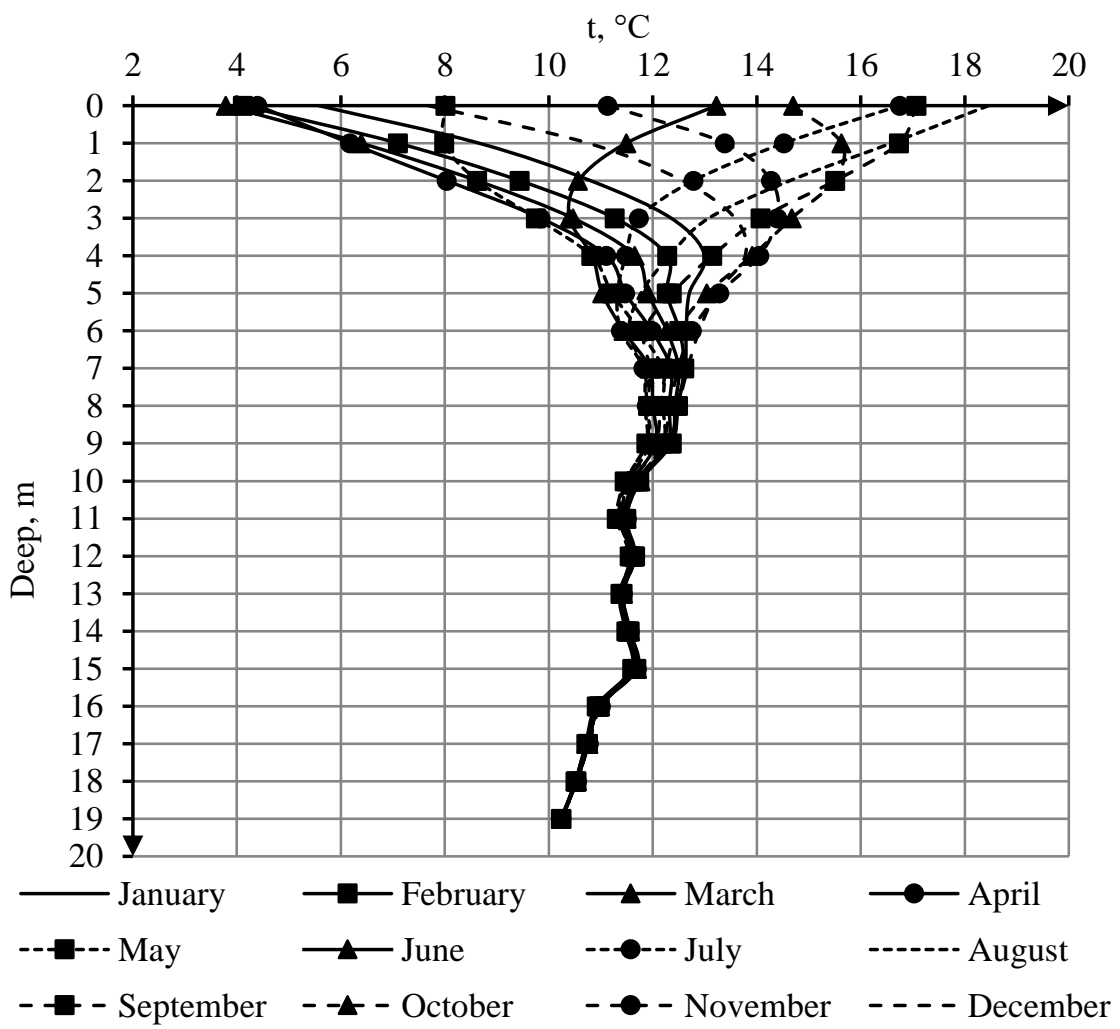

Fig. 2. Site 1. Diagram of average monthly temperatures of soil mass according the monitoring results from 2009 to 2016. 
To gather the data RTM 59 loggers are used for measuring, continuous recording and monitoring of temperature and other non-electrical values (frequency, pressure, flow, level, etc.), converted into electrical signals of strength, DC voltage and DC resistance [7].

The thickness of the observed soil mass on the site 1 is $19 \mathrm{~m}$. The temperature sensors are installed at intervals of $1 \mathrm{~m}$.

Monitoring of temperature fields has held for more than 5 years on the site 1 . Summarized monitoring results (average monthly temperatures for the period from January 2009 to January 2016) are shown in Fig. 2.

Under the diagram the temperature of the soil mass from a depth of $8-9 \mathrm{~m}$ is practically independent of the seasonal outdoor temperature fluctuations. The temperature is about $12^{\circ} \mathrm{C}$, falling to $10^{\circ} \mathrm{C}$ to the depth of $19 \mathrm{~m}$.

To analyze the temperature fluctuations for several annual cycles the average monthly temperatures in September for the 2009 - 2015 is shown in Fig. 3.

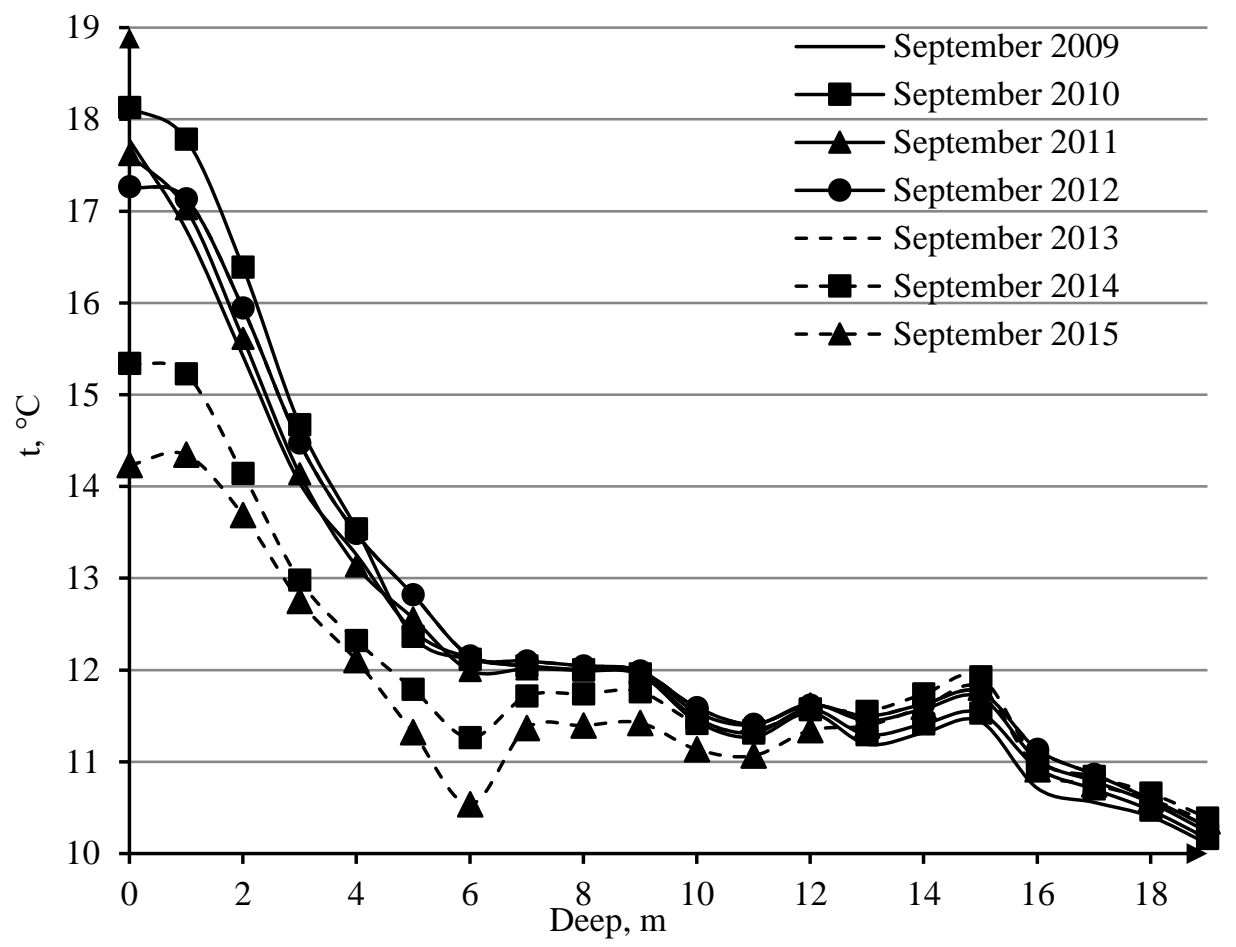

Fig. 3. Site 1. Diagram of average monthly temperatures of soil mass in September for the 2009 2015.

Under the diagram the temperature of the soil mass from a depth of 8-9 $\mathrm{m}$ is constant (difference is not more than $1^{\circ} \mathrm{C}$ ) during 6 years of monitoring. Soil temperatures in September 2015 are explained abnormally low outside temperatures in summer 2015.

The thickness of the observed soil mass on the site 2 is $37 \mathrm{~m}$. The temperature sensors are installed at intervals of $2 \mathrm{~m}$, till a depth of $3 \mathrm{~m}$ interval is equal to $0.5 \mathrm{~m}$.

Monitoring of the temperature fields on the site 2 has carried out since August 2015. Currently monitoring data of temperature distribution in the soil mass were obtained till January 2016. Monitoring results (average monthly temperatures) are shown in Fig. 4. 


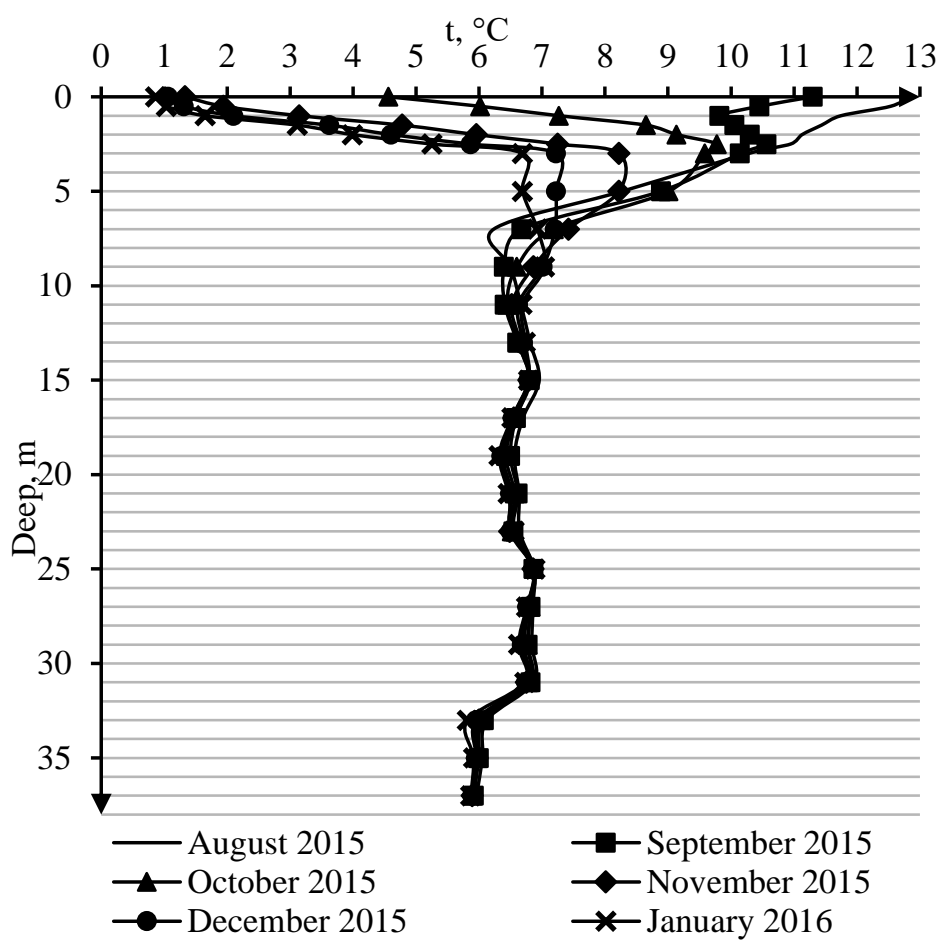

Fig. 4. Site 2. Diagram of average monthly temperatures of soil mass according the monitoring results from August 2015 to January 2016.

Analysis of monitoring results on the site 2 displays that the temperature of soil mass from a depth of $9 \mathrm{~m}$ is constant and equals to $6-7^{\circ} \mathrm{C}$.

For further analysis the average monthly temperatures of soil mass for September 2015 are shown in Table 1 and Fig. 5 for both sites.

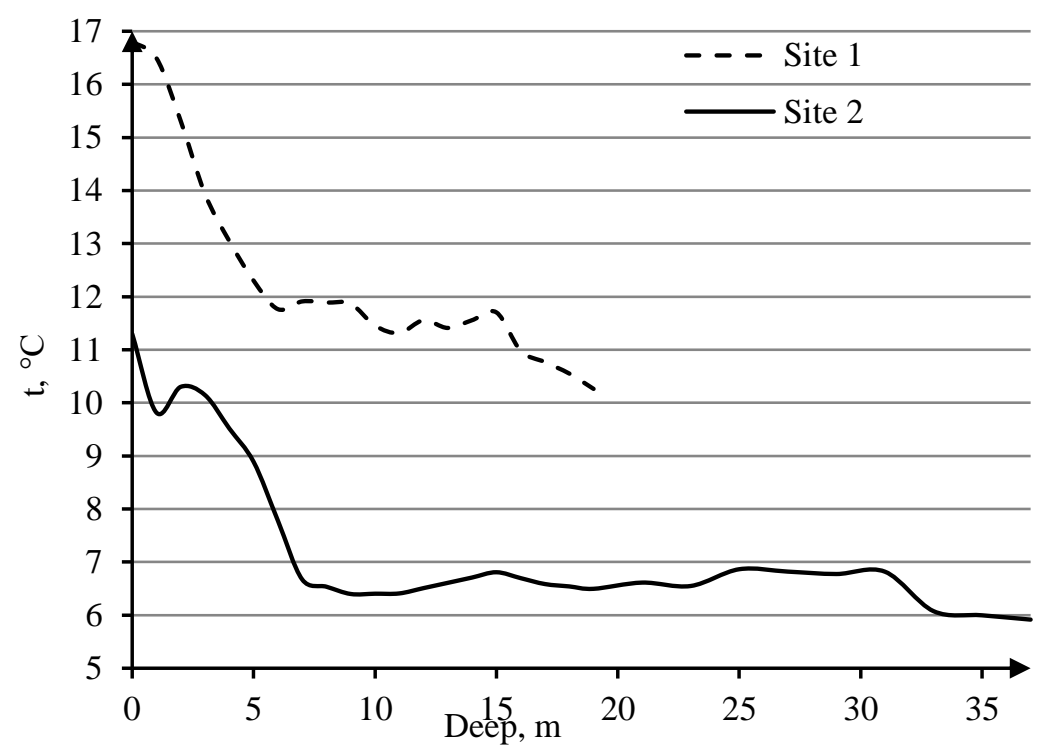

Fig. 5. Diagram of average monthly temperatures in September for sites 1 and 2. 
Table 1. Average monthly temperatures of soil mass in September for sites 1 and 2.

\begin{tabular}{|c|c|c|}
\hline Deep, $\mathrm{m}$ & Site $1,{ }^{\circ} \mathrm{C}$ & Site $2,{ }^{\circ} \mathrm{C}$ \\
\hline 0 & 16.8 & 11.3 \\
\hline 1 & 16.5 & 9.8 \\
\hline 2 & 15.3 & 10.3 \\
\hline 3 & 13.9 & 10.1 \\
\hline 4 & 13.0 & - \\
\hline 5 & 12.3 & 8.9 \\
\hline 6 & 11.8 & - \\
\hline 7 & 11.9 & 6.7 \\
\hline 8 & 11.9 & - \\
\hline 9 & 11.9 & 6.4 \\
\hline 10 & 11.5 & - \\
\hline 11 & 11.3 & 6.4 \\
\hline 12 & 11.6 & - \\
\hline 13 & 11.4 & 6.6 \\
\hline 14 & 11.6 & - \\
\hline 15 & 11.7 & 6.8 \\
\hline 16 & 11.0 & - \\
\hline 17 & 10.8 & 6.6 \\
\hline 18 & 10.6 & - \\
\hline 19 & 10.3 & 6.5 \\
\hline 21 & - & 6.6 \\
\hline 23 & - & 6.5 \\
\hline 25 & - & 6.9 \\
\hline 27 & - & 6.8 \\
\hline 39 & - & 6.8 \\
\hline 31 & - & 6.8 \\
\hline 33 & - & 6.1 \\
\hline 35 & - & 6.0 \\
\hline 37 & - & 6.9 \\
\hline & & \\
\hline
\end{tabular}

\section{Conclusions}

According to the results of conducted studies the following conclusions were drawn:

1. The temperature of soil mass from a depth of $9 \mathrm{~m}$ is constant and equals to $6-7^{\circ} \mathrm{C}$. The temperature fall has not been recorded at depths 7-37 $\mathrm{m}$, in contrast to the site 1 .

2. The temperature of the soil mass for the site 2 is lower than for the site 1 on average of 4- $6^{\circ} \mathrm{C}$. The difference of temperatures decreases with increasing depth.

3. The fixed difference of soil mass temperatures of the sites, are probably explained by the presence of additional heat sources at the site 1 , in particular site 1 is characterized by dense urban development.

4. When designing power efficient foundations and underground structures the location of the object, the presence of surrounding buildings, engineering services should be taken into account.

\section{References}

1. H. Brandl, D. Adam, R. Markiewicz, Acta Geotechnica Slovenica 3 (2006) 
2. R. Katzenbach, D. Adam, T. Waberseck, Geothermie-Symposium "ErdwärmeEnergieträger der Zukunft”, Bremerhaven (2002)

3. V.G. Shapoval, B.V. Morklyanyk, The temperature field in the soil base of heat pumps: monograph (Porohy, Dnepropetrovsk, 2011)

4. A.B. Ponomaryov, A.V. Zakharov, Bulletin of Volgograd State University of Architecture and Civil Engineering. Series: Civil Engineering and Architecture 17(36) (2010)

5. A.V. Zakharov, Bulletin of civil engineers 2 (23) (2010)

6. A.B. Ponomaryov, S.V. Kaloshina, On the geotechnical conditions of construction in the city of Perm. Problems of soil mechanics and foundation engineering in difficult ground conditions, Proc. of the International Scientific Conference dedicated to the 50th anniversary of BashNIIstroy (2006)

7. A.B. Ponomaryov, A.V. Zakharov, PNRPU Bulletin, Applied ecology, Urban development 4 (2011) 